\title{
Polynesian Navigation and Logic
}

\author{
from Andrew Sharp
}

D. H. Lewis, in his article 'Ara Moana: Stars of the Sea Road' in the July 1964 issue of the Journal of the Institute of Navigation (pp. 278-88), speculates on how the Polynesians could have navigated to known distant destinations, but does not explain how the knowledge of the distant destinations on which he relies for his theories was gained by the supposed navigators. Before anybody can navigate to somewhere, someone must first have gone there and come back. Lewis does not tell us how the Polynesians gained their knowledge of the existence, location and size of New Zealand and Hawaii, and of the currents on these courses, on their outward voyages of discovery, and then used this knowledge to get home again. His statement that 'it seems probable that the Polynesians steered by horizon stars until the zenith star showed that they had reached the right latitude, and then turned east or west', obviously has no application to voyages of discovery which by definition were made without prior knowledge of the existence, latitude or size of the objectives. The alternative supposition that the discoverers were able to keep account of their courses from bearings on stars which were reputedly aligned with the destinations and the home islands overlooks the fact that such star bearings gave no clue whatever to longitudinal displacement. There was no practicable method whereby the discoverers could have known the longitudinal relationships of their discoveries and their home islands. The trial voyages which Lewis thinks would be appropriate as a modern test would have no applicability to the circumstances of prehistoric discovery, because they would be made with prior knowledge of the existence and location of the objectives. The diagrams used by Lewis are taken straight from modern European maps and therefore have no relevance to the circumstances attending prehistoric discovery. The notion that prehistoric explorers would have gone on for hundreds and indeed thousands of miles in order to find islands which they did not know existed, knowing that if they did not find them they would have to try to get home again without rest or re-fit, is not a little ridiculous in itself.

The illogicalities which underlie Lewis's contentions are shared by him with a long line of predecessors, including a number of the authorities cited by him in his article.

\section{Southerly Error in Early Explorers' Latitudes in the South Pacific}

\author{
from Andrew Sharp
}

I HAVE read with interest Colin Jack-Hinton's article 'The Use of Apparent Consistency in Errors of Latitude in the Identification of 16 th and 17 th Century Pacific Islands Discoveries' in the July 1964 issue of the Journal of the Institute of Navigation (Pp. 3 I I-I 3). Jack-Hinton takes as his main target the two instances in my book The Discovery of the Pacific Islands in which I used persistent or steady 